\title{
Camellia as an Oilseed Crop
}

\author{
Haiying Liang ${ }^{1}$ \\ Department of Genetics and Biochemistry, Clemson University, Clemson, SC 29634 \\ Bing-Qing Hao, Guo-Chen Chen, Hang Ye, and Jinlin Ma ${ }^{1}$ \\ Guangxi Forestry Research Institute, Guangxi Key Laboratory of Non-wood Cash Crops Cultivation and Utilization, \\ Nanning, P.R. China, 530002
}

Additional index words. biodiesel, cultivar, edible oil, new horticultural crop, oil camellias

\begin{abstract}
Camellia is one of the four main oil-bearing trees along with olive, palm, and coconut in the world. Known as "Eastern Olive Oil," camellia oil shares similar chemical composition with olive oil, with high amounts of oleic acid and linoleic acid and low saturated fats. Camellia was first exploited for edible oil in China more than 1000 years ago. Today, its oil serves as the main cooking oil in China's southern provinces. Introduction of camellia oil into the Western countries was delayed until the recognition of its many health benefits. Although popularity for the oil has yet to grow outside of China, interest has emerged in commercial production of camellia oil in other countries in recent years. Unlike seed-oil plants that are grown on arable land, oil camellias normally grow on mountain slopes. This allows the new crop to take full usage of the marginal lands. To facilitate promoting this valuable crop as an alternative oil source and selecting promising cultivars for targeted habitats, this paper reviews the resources of oil camellias developed in China, use of by-products from oil-refining process, as well as the progress of developing camellias for oil production in China and other nations.
\end{abstract}

The genus Camellia comprises a group of about 100 species native to a number of areas throughout China, southeast Asia, and Japan (Min and Bartholomew, 2007; Ming, 2000). They are evergreen flowering trees or shrubs with broad, shiny, dark green leaves, and have primarily a subtropical and warmtemperate distribution. Among them, Camellia sinensis and Camellia japonica are the best internationally known and cultivated species, for tea production and ornamental value, respectively. These two species made their way to the Western world in the 18th century after being cultivated and treasured in the Orient for thousands of years (Cothran, 2004). Currently, there are more than 22,000 camellia varieties or cultivars cataloged in the International Camellia Society (http:// www.camellia-international.org/). In the United States, there are more than 2300 cultivars registered with the American Camellia Society (https://www.americancamellias. com/). Spain produces about 2.5 million camellia plants annually, mostly C. japonica, which are exported throughout Europe as ornamentals (Salinero et al., 2012). Because of its popularity, many countries and regions, including China, Japan, Korea, Vietnam, Belgium, Haiti, Rwanda, the United States, Albania, France, New Zealand, Poland, Australia, Spain, the Marshall Islands, and the island of Jersey, have issued postage stamps honoring the importance of the camellia

Received for publication 10 Nov. 2016. Accepted for publication 25 Jan. 2017.

We would like to acknowledge the support from the Distinguished Expert Special Fund for the award, Physiology of Flowering of Major Cash Non-wood Crop Species in Guangxi Zhuang Autonomous Region, P.R. China, and Clemson University, Clemson, SC. We also thank Yun Li from Beijing Forestry University, China, for her assistance with Figure 3.

${ }^{1}$ Corresponding authors. E-mail: hliang@clemson. edu or majinlin009@163.com.
(Marshall Islands Press Release, 2013; Rolfe, 1992; http://www.stampnews.com/stamps/ stamps_2013/stamp_1357919298_398033. html; http://www.wnsstamps.post/en/stamps/ AU007.03).

In contrast to its worldwide contributions as an ornamental plant and as a tea producer, camellia oil is less known to the world despite it has long been important in China, as well as in Japan, however, to a lesser extent. Camellia is one of the four main oil-bearing trees along with olive, palm, and coconut in the world (Robards et al., 2009). Oil from camellia seeds is also known as "Eastern Olive Oil," because it shares similar chemical composition with olive oil, with high amounts of oleic acid and linoleic acid, and low saturated fats. Camellia was first exploited for edible oil in China more than 1000 years ago (Shanan and Ying, 1982). Today, camellia oil serves as the main cooking oil in China's southern provinces (Fig. 1), especially in Hunan Province (Ruter, 2002), and more than $90 \%$ of global camellia oil production is from China (Zhao et al., 2015).

Depending on the species, cultivar, and environmental conditions, oil content in
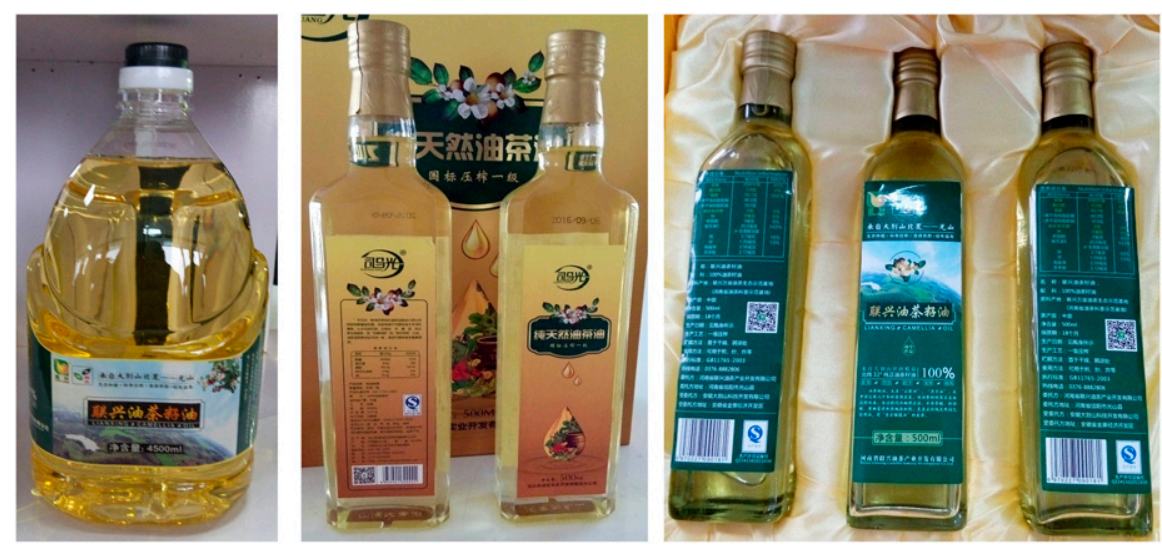

Fig. 1. Examples of edible camellia oil. seeds of traditional camellia varieties can range between $24 \%$ and $50 \%$ with an average of $\approx 30 \%$ (Huang et al., 2013). Some of the new Camellia oleifera cultivars can reach $53 \%$ oil per dry seed (Yang et al., 2016). Camellia oil has a relatively high smoke point when compared with commercial oils such as olive oil, at a range of $210-252{ }^{\circ} \mathrm{C}$ (Allen, 2015; Miao et al., 2013; Zheng et al., 2011), which makes it suitable for deep frying, stir frying, and as a salad dressing. The nutritional value of camellia oil is well documented. The unsaturated fatty acid content in camellia oil complies completely with the international nutritional standards of "omega meals," and can reach as much as $90 \%$ $(\approx 80 \%$ oleic acid, $\approx 10 \%$ linoleic acid, and linolenic acid) (Mondal, 2013), which may be the highest amount so far reported in edible oil (Feas et al., 2013). Its monounsaturated fatty acid and vitamin $\mathrm{E}$ contents are greater than that of olive oil. In addition, camellia oil contains other functional components such as saponins, polyphenol, and squalene. Its beneficial effects have been recently reviewed and summarized in $\mathrm{Li}$ et al. (2011), which include antitumor, reducing 
blood lipid, protecting liver and heart, antisepsis, anti-inflammation, coronary heart disease prevention, delaying atherosclerosis, antioxidation, and immune function regulation. Thus, camellia oil has also long been used in the production of traditional Chinese medicines, cosmetics, soaps, and hair oil.

With growing recognition of its nutritional value, there is a growing demand for camellia oil. The cultivation acreage in China is expected to reach 6.5 million hectares with an annual camellia oil production of 2.5 million tons by 2020 (China Forestry Bureau, 2009). Interest has also emerged in the commercial production of camellia oil in Western nations, such as the United States and Australia (Robards et al., 2009; Ruter, 2002, 2011). The Food and Agriculture Organization of the United Nations has recommended camellia oil as a high-quality, healthy vegetable oil (Ahmed and Wang, 2015). This paper reviews the resources of oil camellias developed in China, by-products from oil-refining process, as well as the progress of developing camellia for oil production in China and other countries.

\section{Major Oil Camellia Species and Resources in China}

Seeds of all camellia species contain oil (Robards et al., 2009). However, oil content and quality may vary with species. In China, the species being cultivated for oil production include $C$. oleifera Abel, $C$. meiocarpa $\mathrm{Hu}, C$ vietnamensis Huang, $C$. chekiangoleosa $\mathrm{Hu}$, C. yuhsienensis $\mathrm{Hu}$, $C$. semiserrata Chi, $C$. reticulata Lindl, $C$. polyodonta How ex Hu, C. gigantocarpa $\mathrm{Hu}, C$. octopetala $\mathrm{Hu}, C$. semiserrata var. albiflora $\mathrm{Hu}$ et Huang, C. phellocapsa Chang et Lee, C. pitardii Coh Stuart, $C$. crassissima Chang et Shi, C. nanyongensis $\mathrm{Hu}, C$. subintegra Huang, C. rhytidocarpa Chang et Liang, $C$. weiningensis Y. K. Li, $C$. chrysantha Hu Tuyama, C. brevituba Chang et Zeng, C. lutca Chang, C. taishunensis Hu, and $C$. osmantha.

Camellia oleifera is the earliest species exploited for edible oil and accounts for $98 \%$ of the cultivated area in China, followed by C. meiocarpa (Yao et al., 2005). Camellia osmantha is a new promising species recently discovered by our group at Guangxi Academy of Forestry, China (Ma et al., 2016). Our preliminary studies (Wang et al., 2014) suggest that $C$. osmantha trees grow fast and can tolerate drought, flooding, and high temperatures. Their flowers and fruits are abundant, with an average of $2.65-\mathrm{kg}$ fresh fruit per square meter tree crown of a 5-year-old seedling. The average oil content in kernel is $46.3 \%$. This would produce $1590 \mathrm{~kg}$ of oil per hectare, doubling the standard oil productivity rate for $C$. oleifera elite cultivars $\left(750 \mathrm{~kg} \cdot \mathrm{ha}^{-1}\right)$. We started to evaluate this new species in 2011 and have planted $\approx 67$ ha in Guangxi Zhuang Autonomous

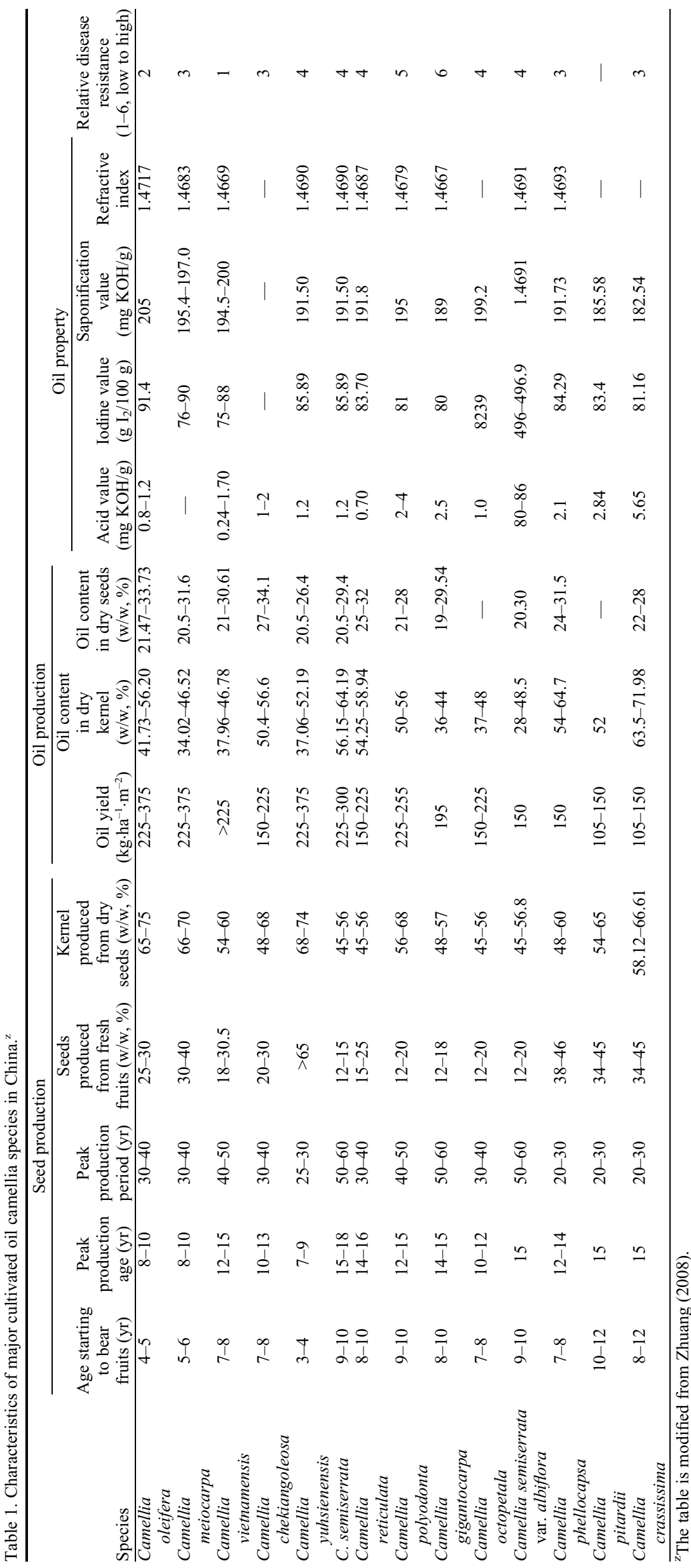



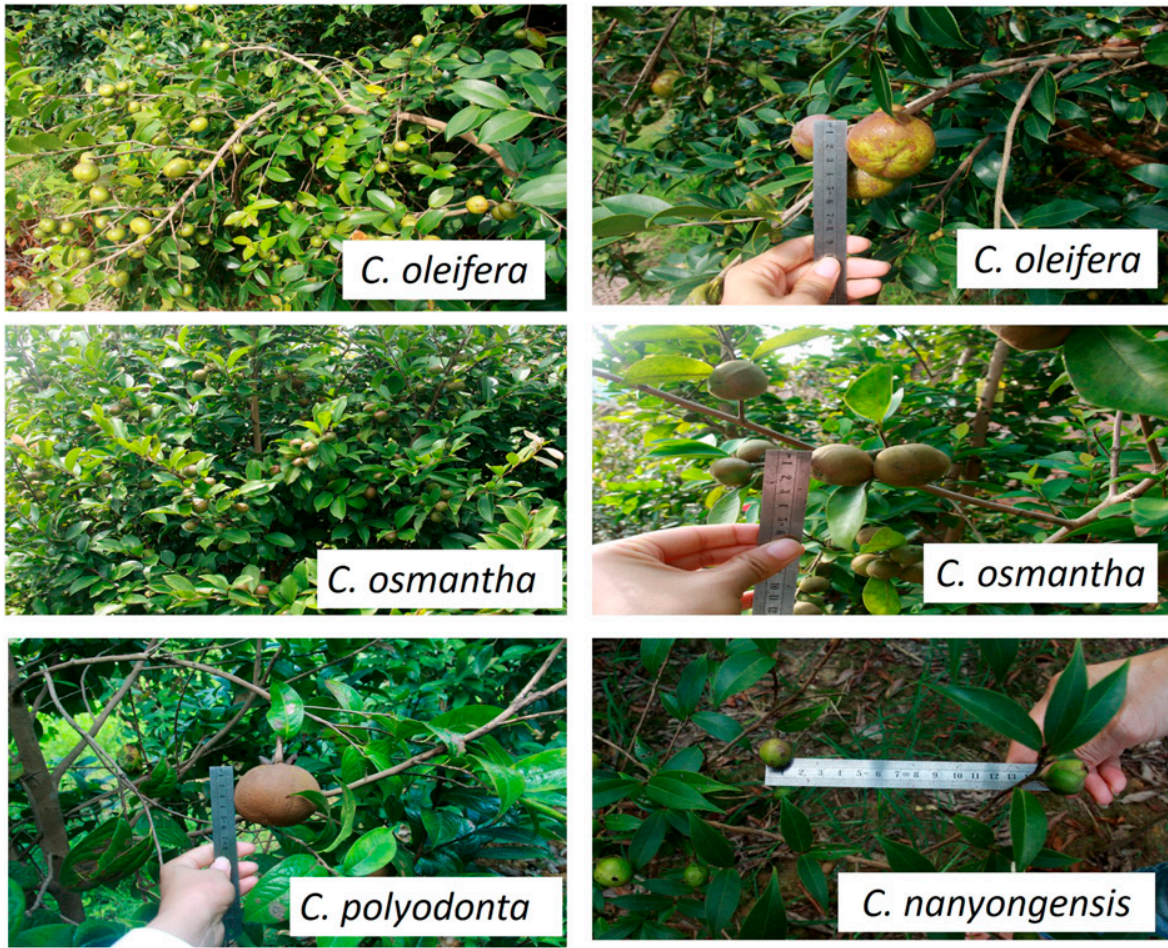

Fig. 2. Fruits of seven oil camellia species. The numbers on the ruler represent centimeters $(\mathrm{cm})$.

Region. Most oil camellias begin bearing fruit in 3 to 6 years after planting and fruit production can last 50-60 years. Characteristics of major oil camellia species are listed in Table 1. Figure 2 shows the fruits of seven oil camellia species.

In China, intense and concerted activities to promote camellias for oil production started in 1960s and the total cultivation once reached over 4 million hectares (Fang, 1994). The research was halted in around 1990 due to lack of funding but has been resumed since 2000. Several decades' efforts have generated many resources. For instance, more than 200 superior clones and pedigrees and more than 100 superior clones and landraces have been collected by the Academy of Forestry of Hunan Province and Jianxi Province, respectively; 30 cutting and three seed orchards have been established nationwide, totaling an acreage of 294 ha with a capacity of providing 75 million superior scions and 136 million seedlings annually (China Forestry Bureau, 2009). Extensive trials and varietal selections in various provinces have also resulted in 55 elite $C$. oleifera varieties that have been certified by the China Forestry Bureau, and another 120 certified at the provincial level (China Forestry Bureau, 2009). The characteristics and suitable planting areas of the 55 state certified $C$. oleifera varieties are outlined in Table 2.

The total cultivation acreage of oil camellia species in China reached 3.83 million ha in 2013 , with an oil output of $\approx 0.4$ million tons. The camellia oil production is expected to reach 0.63 million tons in 2017. The revenue generated by this industry has increased from 11 billion Yuan $(\approx$ U.S.\$1.7 billion) in 2008 to 39 billion Yuan ( $\approx$ U.S.
$\$ 6.1$ billion) in 2013 (Jiao, 2013). The cultivation is distributed in 12 provinces, one autonomous region, and one direct-controlled municipality that are located in the Yangtze River and Pearl River basins of south central and southern China (Fig. 3). Jiangxi, Hunan, and Guangxi are the main growing areas, accounting for $76.2 \%$ of the total cultivation acreage in China. Because of the large population in China, the current production capacity can only provide $\approx 0.5 \mathrm{~kg}$ camellia oil per capita per year. To meet the increasing demand, the Chinese government authorities have given high priority to developments of woody oil-bearing plants, with oil camellias included. A 10-year strategic plan was introduced in late 2009. The goals are to expand cultivation acreage to 6.5 million ha and generate 2.5 million tons of camellia oil by 2020 (China Forestry Bureau, 2009). Currently, the average oil productivity is only $87 \mathrm{~kg} \cdot \mathrm{ha}^{-1}$ per year. This number is expected to increase to 375 or 600 depending on the types of plantations. It is noteworthy that camellias are grown in hills and mountains in China, which belong to forest lands (Fig. 4). Thus, growing camellias for oil production is not competing for arable lands. Instead, it can help decrease soil erosion in hilly regions, improve air quality, and generate income for local farmers.

\section{Utilization of By-products in China}

Camellia nut shells. The current camellia oil processing industry generates nearly 8 million tons of camellia nut shells annually. Accounting for more than $60 \%$ weight of the whole fruit (Qiu et al., 2009), Camellia nut shells contain $13.87-20.95 \%$ cellulose, $34.21-$
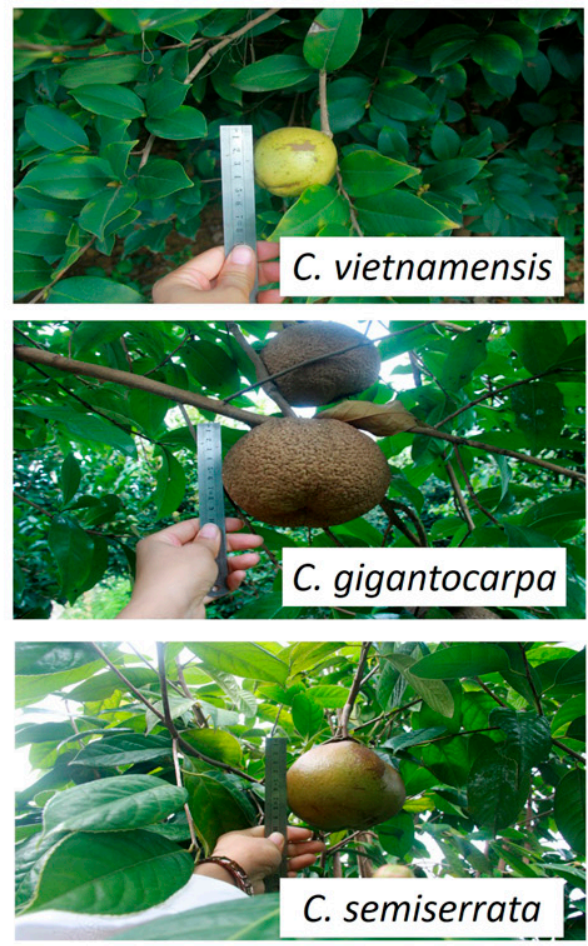

49.34\% hemicellulose, 30.07-36.23\% lignin, $2.00-4.75 \%$ ash, and $2.36-7.76 \%$ organic extracts, depending on the species (Zhang et al., 2015). Zhang et al. (2008a) identified 46 compounds in the camellia nut shells with a Py-GC/MS method, including saponins, polyphenols, and flavonoids. In particular, C. oleifera nut shells contained $>317 \mathrm{mg} \cdot \mathrm{g}^{-1}$ polysaccharide, $>35 \mathrm{mg} \cdot \mathrm{g}^{-1}$ flavonoids, $>292$ $\mathrm{mg} \cdot \mathrm{g}^{-1}$ saponin, $>252 \mathrm{mg} \cdot \mathrm{g}^{-1}$ polyphenol, $272.99 \mathrm{mg} \cdot \mathrm{g}^{-1}$ condensed tannin, and $135.36 \mathrm{mg} \cdot \mathrm{g}^{-1}$ hydrolysis tannin content in its extract (Li et al., 2013). Currently, camellia nut shells are generally burned as fuels. To better use this resource, there is an increasing interest in extracting pigments, tannin, and polyphenols from this material. Some studies have demonstrated the potential of camellia nut shells as animal feed, cultivation substrate (such as for growing mushrooms), and absorbent (activated carbon) (e.g., Sun et al., 2010; Ying et al., 2015). Recently, Zhang et al. (2015) have provided a thorough review on this aspect and proposed a novel application strategy to covert camellia nut shells into high value biomasses. It is important to develop systems with industrial scale to efficiently use the resource, considering that more and more camellia nut shells will be generated in the near future with the rapid development of camellia oil industry. Improper disposal of the materials can impose a serious environmental pollution problem. Dry camellia nut shells are currently sold at a price of 249 Yuan $(\approx \$ 35)$ per ton on the Chinese market.

Defatted camellia seed residue. After camellia seeds are crushed for oil extraction, the residue is usually compressed into a cake shape (Fig. 5) for easy transportation. In 


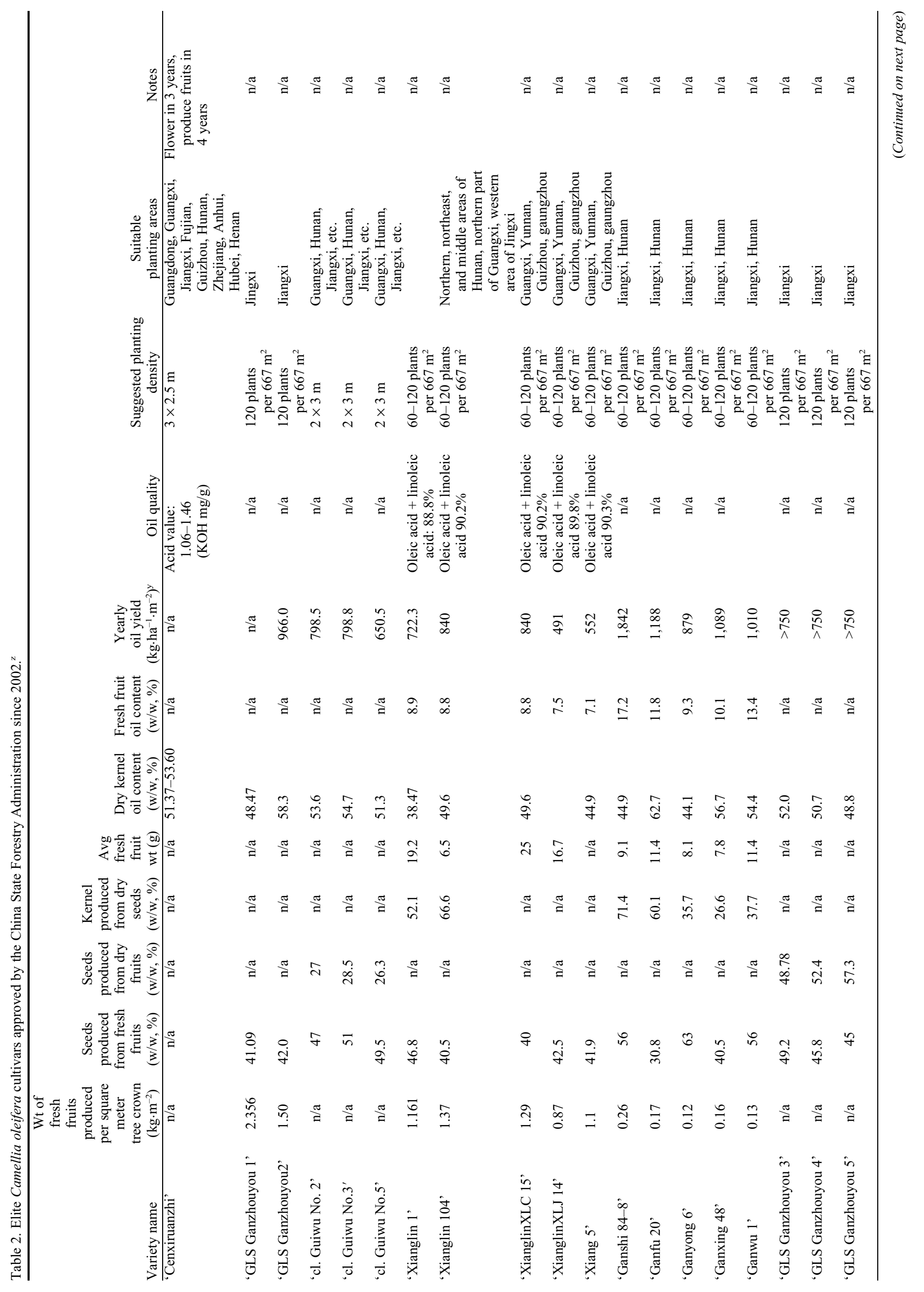

HortScience Vol. 52(4) April 2017 


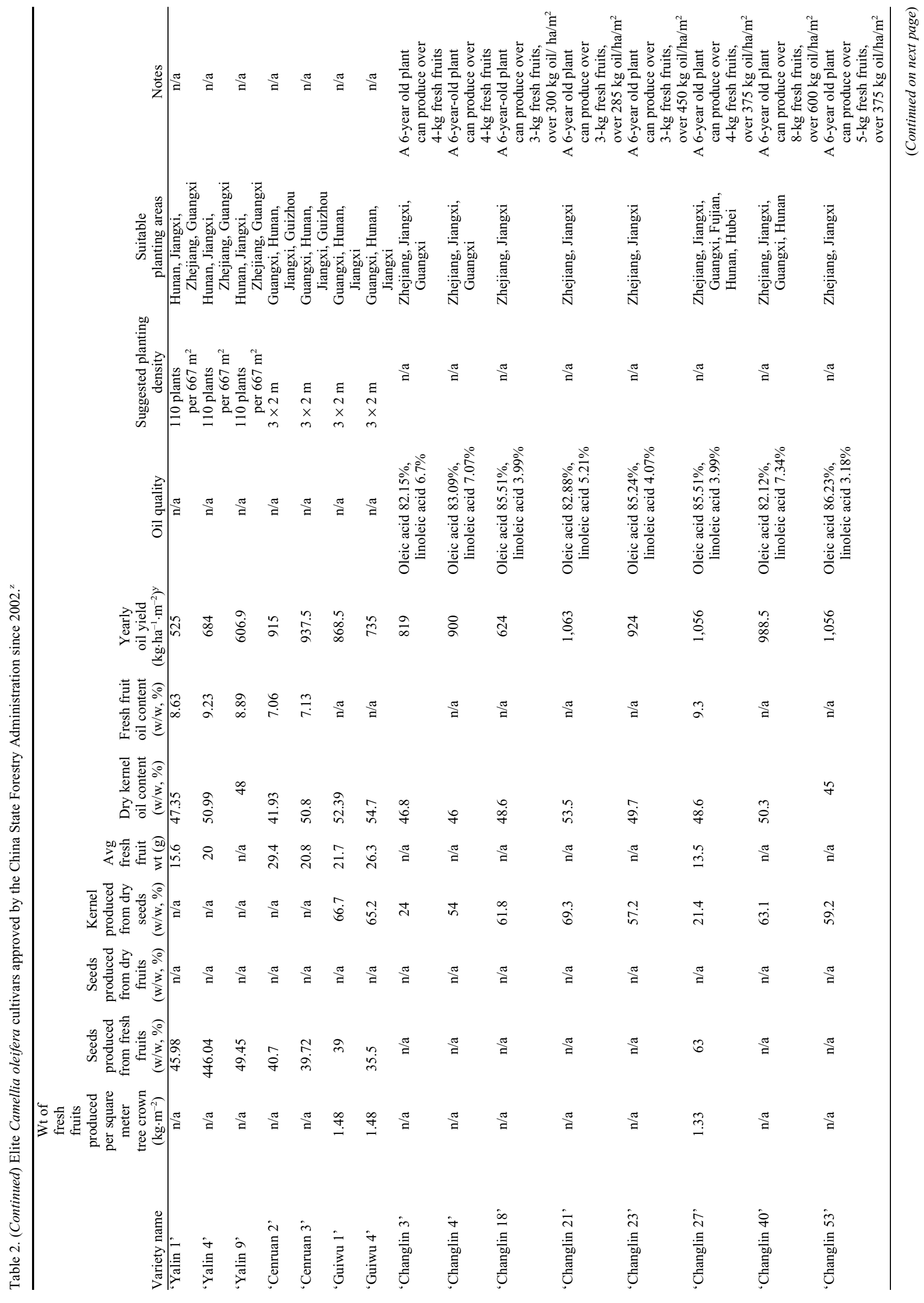




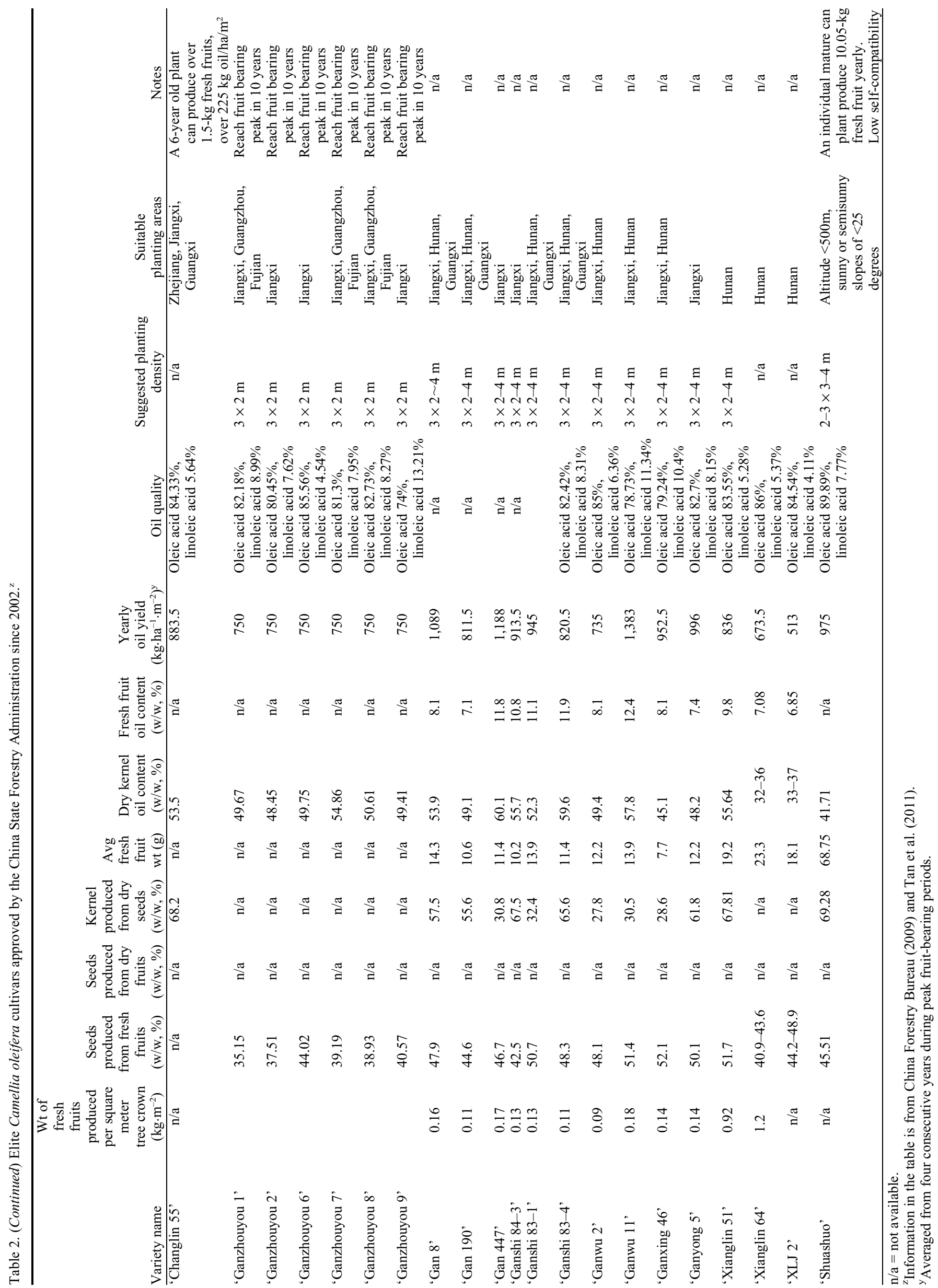




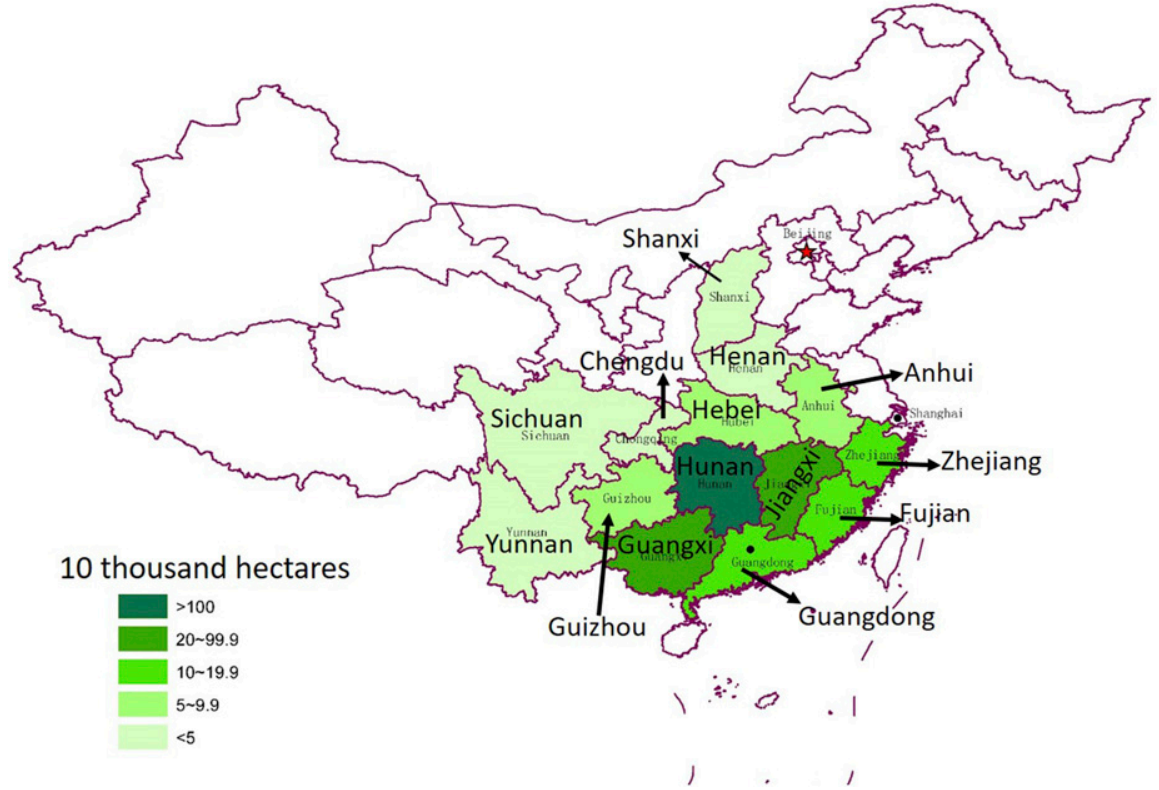

Fig. 3. Distribution of cultivation of oil camellias in China.
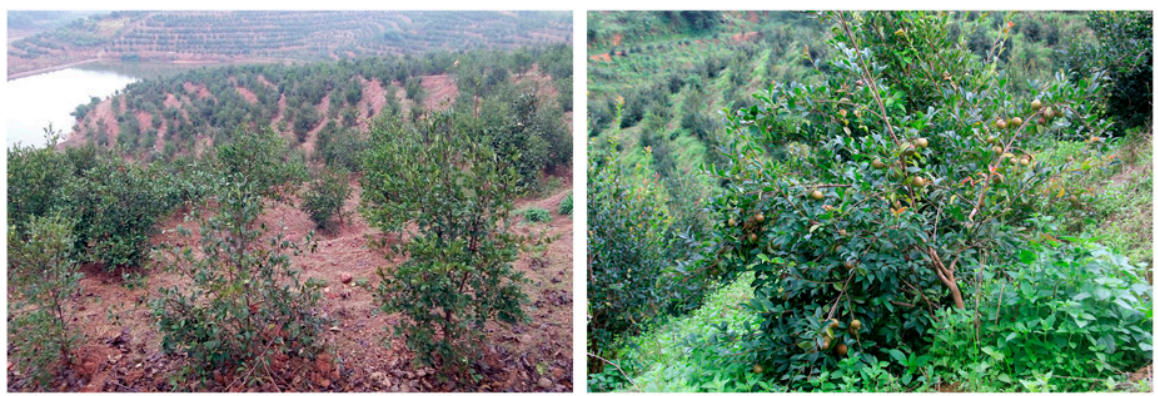

Fig. 4. Oil camellias grown on hilly lands in China.

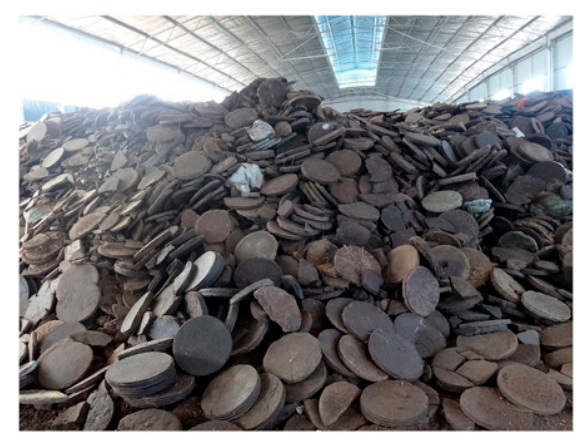

Fig. 5. Defatted camellia cakes, a by-product from camellia oil refining process. The photo was provided by Zhe-Peng Jiang from Guangxi Forestry Research Institute, China.

2009, 0.68 million tons of defatted camellia cakes were produced in China (China Forestry Bureau, 2009). The current price in China is 1800 Yuan $(\approx \$ 281)$ per ton. The residue usually contains $14.30 \%$ water, $6.89 \%$ fat, $12.12 \%$ proteins, $20.00 \%$ fibers, $12.80 \%$ saponins, $27.60 \%$ polysaccharides, and $6.26 \%$ ash (Zhuang, 2008). The cakes may be ground to powders or pellets and are commonly used to formulate pesticides, provide effective control of many pests, including rice blast, sheath and culm blight of rice, wheat rust, rice hopper, cutworms, earthworms, cotton aphids, scale insects, longhorned beetles, golden apple snails, and leeches (Martín et al., 2008; Potter et al., 2010; Shanan and Ying, 1982). In aquaculture, the residue can be used to eliminate predatory fish in prawn ponds.

It is worthy to point out that the remaining oil in camellia cakes can be extracted with solvents: $50-\mathrm{kg}$ residue can produce $2.5-3 \mathrm{~kg}$ oil. The residue then can be extracted with water or solvents for saponins, which have strong antimicrobial activities (Robards et al., 2009). After these two rounds of extraction, the remaining residue still can be used as animal feeds and fertilizers. According to Zhong et al. (2001) and Robards et al. (2009), there is little nutritional loss after ethanol extraction of saponins from camelliadefatted cakes. Microbes, such as Aspergillus niger, Mucor mucedo, Candida utilis, Pleurotus ostreatus, and Auricularia polytricha, can grow and ferment camellia-defatted cakes after removal of saponins with a net protein increase of $66.7 \%$ to $99.7 \%$ and a balanced amino acid composition.
As a multipurpose plant, camellias are a valuable cash crop. Compared with oil processing, infrastructure for fully using its by-products is currently not well developed, although relevant studies are on the rise. It is important to improve this area because it has potential impacts on sustainability and economic return for oil camellia plantations.

\section{Cultivation of Oil Camellias in Other Oriental Countries}

In southeast Asian countries where camellia seeds are abundantly available, such as Japan, Korea, India, Sri Lanka, Indonesia, and Vietnam, camellia oil has been accepted as an edible oil (Sahari et al., 2004), however, to a much lesser extent when compared with China. In Vietnam, the common species include $C$. oleifera, $C$. sansanqua, $C$. forrestii, and $C$. vietnamensis, occurring from $16^{\circ} 50^{\prime}$ to $23^{\circ} 21^{\prime}$ north latitude and $103^{\circ} 13^{\prime}$ to $107^{\circ} 21^{\prime}$ east longitude. Large-scale planting started in 1960s. A report by Nguyen et al. (2006) revealed about 6000 ha of plantations. However, oil productivity is low in Vietnam, which is under $500 \mathrm{~kg} \cdot \mathrm{ha}^{-1}$ per year (Hoang et al., 2014). In contrast, oil productivity of intensive oil camellia plantations in China is found to have been as high as $1000 \mathrm{~kg} \cdot \mathrm{ha}^{-1}$ per year (Hoang et al., 2014). Hoang et al. (2014) pointed out that, while oil camellia plantation has an enormous potential for poverty reduction in Vietnam, small-scaled planted areas and instability of oil market are two biggest issues in developing oil camellias in this country. Management measurements, such as replacement with a new canopy by grafting with improved cultivars, thinning, and fertilization, can improve seed productivity and oil ratio and quality (Hoang et al., 2014). In Japan, C. japonica is one of the leading sources for camellia oil production (Jung et al., 2007).

In countries where tea production $(C$. sinensis) is abundant, such as India, Iran, and Turkey, there are extensive research programs to assess the commercial feasibility and characteristics of tea seed oil as a byproduct from tea plantations. According to FAOSTAT, the world tea harvested area totaled 3,521,221 ha in 2013 (FAO database, accessed 6 Oct. 2016). With an average of 3.5 tons of tea seed per hectare collected annually (Demirbas, 2009), there would be 12.3 million tons of seeds. In considering that the oil content of $C$. sinensis seed is 20\% (Ravichandran and Dhandapani, 1992; Singh, 1998), these tea seeds would generate 2.46 million tons of oil

\section{Development of Oil Camellias As an Edible Oil Seed Crop for the United States}

Because of its evidenced effectiveness in warding off heart attack and stroke (Estruch et al., 2013), there is a rising demand of olive oil in markets outside of the Mediterranean region. Global production of olive oil has more than doubled from about 1.5 million metric tons in 1990 to an average of 2.92 
million tons in the last 7 years (International Olive Council). In the United States, consumption of olive oil has tripled over the past 20 years (Xiong et al., 2014). According to the data recently released from the U.S. Department of Agriculture (USDA)-Foreign Agricultural Services, the 2016 U.S. distribution of olive oil is 0.32 million tons (http:// www.fas.usda.gov/psdonline/psdDownload. aspx). Although this number remains a tiny share in U.S. consumption of all vegetable oils, which was more than 13.7 million tons in 2015, the U.S. production of olive oil has remained low. Being the largest import destination for olive oil (excluding intra-EU trade) (Xiong et al., 2014), the U.S. olive industry only supplied 5000 tons of olive oil in 2015 , about $1.5 \%$ of olive oil marketed in the United States, although olive oil has been produced in the United States for more than 150 years (http://www.fas.usda.gov/ psdonline/psdDownload.aspx). Because camellia oil shares similar properties and beneficial effects with olive oil, Ruter and colleagues (Zhang et al., 2008b) have suggested that oil camellias can be a new edible oil seed crop for the United States and help lessen the dependence of olive oil import.

Introduction of oil camellias into the United States. Camellia oleifera, the dominant oil species in China, was first used as a parent of hardy ornamental camellia hybrids in the United States in the late 1970s (Lee, 1998). Since then, the U.S. National Arboretum has released a range of such cultivars (Ackerman, 2007). The most common ones include 'Frost Princess', 'Polar Ice', 'Snow Flurry', 'Winter's Beauty', 'Winter Charm', 'Winter Interlude', 'Winter Rose', 'Winter Star', and 'Winter Waterlily' (Ackerman, 2002; Ackerman and Egolf, 1991, 1992; Ackerman and Williams, 1981; Dirr, 1998). These selections extended the range of camellia into areas with colder winters. However, these cultivars are grown and used only as ornamental landscape plants. Currently, there is no documentation that oil camellias are being commercially grown for edible purposes in the United States.

In 1999, Ruter (2002) started a research program to evaluate $C$. oleifera as a commercial oil seed crop for the southeast. The author located four seed sources in the United States and studied nursery production of $C$. oleifera under different light levels. It was found that container-grown plants of $C$. oleifera could be produced without physiologically damaged by high light conditions in full sun during the summer in south Georgia, although optimal growth occurred under $30 \%$ light exclusion. It was also found that stratification improved rate and uniformity of seed germination, with cold stratification for 45 to $60 \mathrm{~d}$ being ideal for the species (Ruter, 2005). In 2001, the same author acquired seeds from 18 elite selections of camellias grown in China for oil production, including C. oleifera, C. semiserrata, and C. yuhsienensis. These seedlings, as well as the ones from the original four seed sources located in the United States, were planted at the Coastal Plain Station in Tifton and at a farm in Wrightsville, GA, during 2003 and 2005. About 1200 seedlings from five different species were planted from 2.8-L containers using a field spacing of $1.8 \mathrm{~m}$ within the row and $3.7 \mathrm{~m}$ between rows. Results from 4 years of harvest in Tifton and two in Wrightsville, which produced $>3.0 \mathrm{~kg}$ fresh weight of fruit per plant annually, indicated that selections were possible (Ruter, 2011). When evaluated and selected for traits such as oil production and quality, disease and insect resistance, flowering and fruiting dates, ease of harvest, and growth characteristics, these seedlings will provide invaluable materials for more field trials and breeding programs. Other propagation and management practice have also been explored in the United States for oil camellias. For instance, Ruter (2011) reported an average of cutting rooting rate of 93\% and compared effects of fertilizers and lime.

In China, oil camellia occurs from $18^{\circ}$ to $34^{\circ}$ north latitude and grows on various soil types, such as clay, loam, sand, slightly alkaline, acidic, and well-drained soils, where mean January temperatures do not drop below $2{ }^{\circ} \mathrm{C}$ (Shanan and Ying, 1982). Ruter and colleagues (Zhang et al., 2008b) suggested that, in the United States, this group of plants should do well on upland sites, which support traditional tree or row crops and could be cultivated from USDA hardiness zones 6 to 9 (although they rarely set fruit in the southeastern United States above zone $8 \mathrm{~b}$ ), which covers about half of the continental United States (Gilman and Watson, 1993). Because only a few cultivars of oil camellias have been studied in the United States, it is necessary to introduce more elite cultivars and species, especially the ones recently certified by the China Forestry Bureau.

There has been tremendous information on camellia oil quality, processing, pharmaceutical, medical, and nutritional uses, and use of by-products in China. In contrast, only a few similar studies were conducted in the United States. Potter et al. (2010) reported that camellia seed pellets, a saponin-rich byproduct of $C$. oleifera oil manufacture, were an effective botanical vermicide that could be useful for selectively managing earthworm casts on closely mowed turfgrass. Allen (2015) conducted physiochemical analyses of $C$. oleifera oil before and after thermal degradation. His data indicated that camellia oil exhibited a high degree of heat stability relative to peanut and soybean oils. More research is needed in the United States.

It is noteworthy that cultivation and breeding activities of oil camellias in other Western countries have not been reported. However, there has been an increasing interest in camellia oil as evidenced by increasing studies on its nutritional composition, bioactivity, and extraction and processing techniques conducted by researchers in Western countries, as well as by their collaboration with Chinese scien- tists (De Ron et al., 2014; Feas et al., 2013; Huang et al., 2013; Lee and Di Gioia, 2009; Rajaei et al., 2005; Robards et al., 2009; Zhong et al., 2007). The American Camellia Society is currently planting a new garden featuring those Camellia species that are grown for oil (https://www.americancamellias. com/massee-lane-gardens/visiting-the-gardens/ camellia-garden). Most studies conducted outside of China focused on seeds from $C$. sinensis, $C$. japonica, and $C$. sasanquas. These species are globally cultivated mainly for tea production or ornamental value, and their seed oil content is relatively low, with $15 \%$ to $25 \%$ for $C$. sinensis (George et al., 2013), 20.8\% for $C$. japonica (De Ron et al., 2014), and $30.4 \%$ for C. sasanqua (Vela et al., 2014).

\section{Potential of Camellia Oil As an Alternative to Vegetable Oil for Use As Raw Oil in Biodiesel Production}

Unlike seed-oil plants that are grown on arable land, such as rapeseed, peanut, sunflower, and soybean, oil camellias can be planted on infertile mountainsides, thus potentially constitutes another abundant source of raw oil to meet biodiesel production demand. Although this potential has yet to be demonstrated, targeted research are on the rise. Recently, a criterion that is in accordance with standards of China, the United States, and Germany has been developed for testing camellia biodiesel (Zheng et al., 2011). Allen (2015) reported that biodiesel produced from $C$. oleifera waste oil was comparable to soybean. When prepared through supercritical-methanol transesterification, oleic acid (C18:1) and palmitic acid (16:0) were the two major components of C. oleifera oil biodiesel, which contained higher monounsaturated fatty acids and long carbon-chain fatty acids ranging from C20 to $\mathrm{C} 22$ than those found in a commercial biodiesel produced from waste cooking oil and with ASTM No. 2D diesel fuel (Lin and Fan, 2011). The camellia diesel also had more favorable fuel properties than the commercial biodiesel produced from waste cooking oil, including a higher heat of combustion and flash point, much lower peroxide and acid values, lower levels of kinematic viscosity, water content, carbon residue, and poly-unsaturated fatty acids, with more than three double bonds (Lin and Fan, 2011). Demirbas (2009) reported that biodiesel from C. sinensis itself is not significantly different from biodiesel produced from vegetable oils and is one of the cheapest vegetable oil feedstocks with an average price of U.S. $\$ 514$ per ton (Demirbas, 2010a, 2010b). A study on performance and emissions of a diesel engine fueled with $C$. sinensis oil biodiesel-diesel fuel blends showed that up to $20 \%$ volumetric content of tea seed biodiesel could be effectively used in fuel mixture (Serin and Akar, 2014). Some studies focused on use of defatted camellia cakes for biofuel production. As a by-product from camellia oil refining process, the defatted 
cakes contain significant concentrations of residual lipids and organic matters (Zhuang, 2008). A study by Chen et al. (2015) showed that liquefaction in ethanol at $300{ }^{\circ} \mathrm{C}$ was a promising process for producing bio-oil from defatted camellia cakes.

\section{Challenges Faced in the Oil Camellias Industry}

Despite significant progress since 1960s, further development and growth of the oil camellias industry in China is facing several challenges. According to the reports from the China Forestry Bureau (2009), it costs about $\$ 3200$ per hectare in China to establish a new planation. This investment is relatively high for local farmers, considering that there is no harvest for the first 3 years. About $70 \%$ of current plantations have low productivity, due to factors such as old age, improper management, and use of nonimproved varieties. Depending on the types of renovation measurements, including stem/branch thinning, fertilizing, and changing canopy by grafting, the cost can range from $\$ 430$ to $\$ 4290$ per hectare (China Forestry Bureau, 2009). Also, the fact that oil camellias have been commonly grown by individual local farmers on scattered hilly lands in the past decades makes mechanization difficult and costly. Currently, planting, fruit/nut picking, and shell peeling are mostly done manually. Since China is now experiencing the largest mass migration of people from the countryside to the city in history- $16.5 \%$ of all citizens according to the 2010 census and more than 100 million more farmers would move to urban areas over the next decade, according to the China Labor Bulletin at china-labor.org, farm labor shortage is making the low level of mechanization in the oil camellias industry a bigger issue than ever. To make camellia oil as competitive as the better known soybean and peanut oil in the market, these major challenges need to be addressed. In addition, more research is required to improve efficiency associated with crushing of the seeds and oil extraction.

The key to success in growing oil camellias in different regions of the world is to identify promising clones with high yield and oil quality for targeted habitats (Zhang et al., $2008 \mathrm{~b}$ ). This process will require a good deal of selections and trials. A good place to start is with those varieties has selected for similar climates in China and other Asian countries. Since labor cost is much higher in the Western countries, such as the United States, than in China, a centralized operating system with high level and efficiency of mechanization may be essential for the industry to be profitable in these countries.

\section{Conclusions}

With growing recognition of its nutritional value, there is an increasing demand for camellia oil. China is currently the major producer and user, producing $\approx 0.4$ million tons of camellia oil in 2013. This number is expected to reach 0.63 million tons in 2017 and 2.5 million tons by 2020 . Because of its large population, almost all camellia oil produced in China will continue to be consumed domestically in the near future. Besides oil, camellia seeds are rich in polysaccharides, pigments, tannin, and polyphenols. Both camellia nut shells and defatted seed residue can be used in many applications. Thus, oil camellias have high economic values. Introduction of camellia oil into the Western nations was delayed until the recognition of its many health benefits. Interest has emerged in commercial production of camellia oil in countries such as the United States and Australia in recent years. However, popularity for the oil has yet to grow.

Camellia oleifera is currently the dominant species cultivated for oil production. Several decades' selections and trials have resulted in 55 elite $C$. oleifera cultivars that have been certified by the China Forestry Bureau and another 120 certified at the provincial level. These cultivars are a valuable resource for cultivation. Compared with $C$. sinensis and $C$. japonica, which are widely cultivated for tea production and ornamental value, respectively, oil camellias remain to be introduced to Western countries. Finding cultivars with high yield and oil quality that grow reliably in different regions of the world will require a good deal of selections and trials. A good place to start is with those varieties has selected for similar climates in China and other Asian countries. Not competing for arable land, oil camellias can be planted on infertile mountainsides, thus have the potential to take full usage of the marginal lands in the world.

\section{Literature Cited}

Ackerman, W.L. 2002. Growing camellias in cold climates. Noble House, Baltimore, MD.

Ackerman, W.L. 2007. Beyond the Camellia belt: Breeding, propagating, and growing ColdHardy Camellias. Ball Publishing.

Ackerman, W.L. and D.R. Egolf. 1991. 'Winter's Rose', 'Snow Flurry', and 'Polar Ice' camellias. HortScience 26:1432-1433.

Ackerman, W.L. and D.R. Egolf. 1992. 'Winter's Charm', 'Winter's Hope', and 'Winter's Star' camellias. HortScience 27:855-856.

Ackerman, W.L. and M. Williams. 1981. 'Frost Prince' and 'Frost Princess' camellias. HortScience 16:690.

Ahmed, H.O.A. and C. Wang. 2015. Determination of tea saponin in Camellia seed oil with UV and HPLC analysis. World J. Eng. Technol. 3:30-37.

Allen, C.B. 2015. Thermal degradation and biodiesel production using Camellia oleifera seed oil. Graduate Thesis, University of Georgia.

Chen, H., Y. Zhai, B. Xu, B. Xiang, L. Zhu, P. Li, X. Liu, C. Li, and G. Zeng. 2015. Feasibility and comparative studies of thermochemical liquefaction of Camellia oleifera cake in different supercritical organic solvents for producing bio-oil. Energy Convers. Mgt. 89:955-996.

China Forestry Bureau. 2009. National Plan for the Development of Camellia oil (2009-2020). [EB/ OL] (in Chinese). $<$ http://www.sdpc.gov.cn/zcfb/ zcfbghwb/200911/W020140220607252029036. pdf $>$.
Cothran, J.R. 2004. Treasured ornamentals of southern gardens: Michaux's lasting legacy. Castanea 69(sp2):149-157.

Demirbas, A. 2009. Oil from tea seed by supercritical fluid extraction. Energy Source Part A 31:217-222.

Demirbas, A. 2010a. Tea seed upgrading facilities and economic assessment of biodiesel production from tea seed oil. Energy Convers. Mgt. 51:2595-2599.

Demirbas, M.F. 2010b. Microalgae as a feedstock for biodiesel. Energy Educ. Sci. Technol. Part A 25:31-43.

De Ron, A.M., M.C. Salinero, and P. Vela. 2014 Variation in oil content in Camellia japonica seeds, p. 286-291. Proc. International Camellia Congress, Pontevedra, Spain.

Dirr, M. 1998. Manual of woody landscape plants: Their identification, ornamental characteristics, culture propagation and uses. 5th ed. Stipes Publishing, Champaign, IL.

Estruch, R., E. Ros, J. Salas-Salvadó, M.-I. Covas, D. Corella, F. Arós, E. Gómez-Gracia, V. RuizGutiérrez, M. Fiol, J. Lapetra, R.M. LamuelaRaventos, L. Serra-Majem, X. Pintó, J. Basora, M.A. Muñoz, J.V. Sorlí, J.A. Martínez, and M.A. Martínez-González. 2013. Primary prevention of cardiovascular disease with a Mediterranean diet. N. Engl. J. Med. 368:1279-1290.

Fang, J. 1994. Advances in science and technology on tea oil tree and tung oil tree in China (in Chinese). For. Sci. 7:30-38.

Feas, X., L.M. Estevinho, C. Salinero, P. Vela, M.J. Sainz, M.P. Vázquez-Tato, and J.A. Seijas. 2013. Triacylglyceride, antioxidant and antimicrobial features of virgin Camellia oleifera, C. reticulata and $C$. sasanqua oils. Molecules 18:4573-4578.

George, K.O., T. Kinyanjui, J. Wanyoko, K.M. Okongo, and F. Wachira. 2013. Extraction and analysis of tea (Camellia sinensis) seed oil from different clones in Kenya. Afr. J. Biotechnol. 12:841-846.

Gilman, F. and D.G. Watson. 1993. Camellia oleifera (Tea-oil camellia). US Forest Service Fact Sheet, ST-116.

Hoang, V.T., V.D. Tran, S. Tamotsu, and Q.K. Nguyen. 2014. Tea oil camellia plantation, an enormous potentiality for poverty reduction. Asian J. Agr. Ext. Econom. Socio. 3:1-12.

Huang, J., A. Ahrends, J. He, H. Gui, J. Xu, and P.E. Mortimer. 2013. An evaluation of the factors influencing seed oil production in Camellia reticulata L. plants. Ind. Crops Prod. 50:797802.

Jiao, Y.H. 2013. National camellia oil plantation area has reached 3.83 million hectares (in Chinese). Forestry and Ecology 12:46.

Jung, E., J. Lee, J. Baek, K. Jung, J. Lee, S. Huh, S. Kim, J. Koh, and D. Park. 2007. Effect of Camellia japonica oil on human type I procollagen production and skin barrier function. J. Ethnopharmacol. 112:127-131.

Lee, J. 1998. Lu Shan Snow: The forgotten camellia. Agr. Res. 46(10):21.

Lee, P.J. and A.J. Di Gioia. 2009. Characterization of tea seed oil for quality control and authentication. Waters Corporation Application Note 72000298en. 28 Oct. 2016. <http:// wwwp1.waters.com/webassets/cms/library/ docs/720002980en.pdf>.

Li, H., X.Z. Fang, H.Y. Zhong, X.Q. Fei, and F. Luo. 2013. Tea saponin contents distribution in maturation process of camellia fruit (in Chinese). Cereals \& Oils 26:24-26.

Li, H., G.Y. Zhou, H.Y. Zhang, and J. Liu. 2011. Research progress on the health function of tea oil. J. Med. Plants Res. 5(4):485-489. 
Lin, C.-Y. and C.-L. Fan. 2011. Fuel properties of biodiesel produced from Camellia oleifera Abel oil through supercritical-methanol transesterification. Fuel 90:2240-2244.

Ma, J.-L., H. Ye, and C.-X. Ye. 2016. A new species of Camellia sect. Paracamellia (in Chinese with English abstract). Guihaia 6:753-755.

Marshall Islands Press Release. 2013. <http://www. stampagencies.com/ $>$.

Martín, R.S., K. Ndjoko, and K. Hostettmann. 2008. Novel molluscicide against Pomacea canaliculata based on quinoa (Chenopodium quinoa) saponins. Crop Prot. 27:310-319.

Miao, J., K. Che, R. Xi, L. He, X. Chen, X. Guan, X. Zhuang, X. Wen, and Y. Cao. 2013. Characterization and benzopyrene content analysis of Camellia seed oil extracted by a novel supercritical fluid extraction. J. Amer. Oil Chem. Soc. 90:1503-1508.

Min, T.L. and B. Bartholomew. 2007. Theaceae, p. 412-418. In: Z.Y. Wu, P. Raven, and D.Y. Hong (eds.). Flora of China, Vol. 12. Science Press, Miss. Bot. Gard. Press.

Ming, T.L. 2000. Monograph of the Genus Camellia (in Chinese). Yunnan Science and Technology Press, Kunming, China.

Mondal, T.K. 2013. Camellia, p. 15-39. In: C. Kole (ed.). Wild Crop relatives: Genomics and breeding resources. Springer-Verlag, Berlin, Germany.

Nguyen, Q.K., V.T. Hoang, B.V. Nguyen, and V.T. Nguyen. 2006. Surveying results on development status for tea oil camellia plantation in northern provinces, Vietnam. Vietnam J. for Sci. 3:169-176.

Potter, D.A., C.T. Redmond, K.M. Meepagala, and D.W. Williams. 2010. Managing earthworm casts (Oligochaeta: Lumbricidae) in turfgrass using a natural byproduct of tea oil (Camellia sp.) manufacture. Pest Mgt. Sci. 66:439-446.

Qiu, H.Y., J.M. Chen, and J.R. Hu. 2009. Microwave extraction and stability of brown pigment from Camellia oleifera shells (in Chinese with English abstract). Food Sci. 30:198-202.

Rajaei, A., M. Barzegar, and Y. Yamini. 2005. Supercritical fluid extraction of tea seed oil and its comparison with solvent extraction. Eur. Food Res. Technol. 220:401-405.

Ravichandran, R. and M. Dhandapani. 1992. Composition, characteristics and potential uses of south Indian tea seeds. J. Food Sci. Technol. 29:394-396

Robards, K., P. Prenzler, D. Ryan, and H. Zhong. 2009. Camellia oil and tea oil, p. 313-343. In: R. Moreau and Kamal-Eldin (eds.). Gourmet and health promoting specialty oils. AOCS Press, Urbana, IL.
Rolfe, J. 1992. Gardening with Camellias: A complete guild. Kangaroo Press, Kenthurst, New South Wales.

Ruter, J.M. 2002. Nursery production of tea oil camellia under different light levels, p. 222 224. In: J. Janick and A. Whipkey (eds.) Trends in new crops and new uses. ASHS Press, Alexandria, VA.

Ruter, J.M. 2005. Stratification improves germination of Camellia oleifera. Proc. Southern Nurs. Assoc. Res. Conf. 50:420-421.

Ruter, J.M. 2011. Tea oil camellia: A new edible oil crop for the United States. Proc. 2011 Ann. Meeting Intern. Plant Propagator's Society, Southern Region of North America, Valdosta, GA. 28 Sept. 2016. <http://ipps-srna.org/pdf/ 2011Papers/10-Ruter-John-IPPS\%202011. pdf $>$.

Sahari, M.A., D. Ataii, and M. Hamedi. 2004. Characteristics of tea seed oil in comparison with sunflower and olive oils and its effect as a natural antioxidant. J. Amer. Oil Chem. Soc. 81:585-588.

Salinero, C., X. Feás, J.P. Mansilla, J.A. Seijas, M.P. Vázquez-Tato, P. Vela, and M.J. Sainz. 2012. 1H-nuclear magnetic resonance analysis of the triacylglyceride composition of coldpressed oil from Camellia japonica. Molecules 17:6716-6727.

Serin, H. and N.Y. Akar. 2014. The performance and emissions of a diesel engine fueled with tea seed (Camellia sinensis) oil biodieseldiesel fuel blends. Intl. J. Green Energy 11:292301.

Shanan, H. and G. Ying. 1982. The comprehensive utilization of Camellia fruits. Amer. Camellia Yearbook 37:104-107.

Singh, I.D. 1998. Tea variety development and management in Iran. Food and Agriculture Organization, Rome, Italy, TCP/IRA/6614, p. 185.

Sun, K., J.C. Jiang, Y. He, Y.S. Lin, D.D. Cui, and X.C. Lu. 2010. Preparation of activated carbon from Camellia oleifera shell and its mesoporous structure modification (in Chinese with English abstract). Chem. \& Ind. Forest Prod. 30:24-28.

Tan, X., D. Yuan, J. Yuan, F. Zou, P. Xie, Y. Su, D. Yang, and J. Peng. 2011. An elite variety: Camellia oleifera 'Huashuo'. Sci. Sil. Sin. 47:12.

Vela, P., C. García-Sartal, C. Salinero, and M. González-García. 2014. Camellia oil quality indices from seeds harvested in Pontevedra (NW Spain). Proc. Int. Camellia Congress, Pontevedra, Spain. 22 Oct. 2016. <http://www.internationalcamellia.org/camellia-oil-quality-indices-from-seeds-harvested->
Wang, D.-X., H. Ye, J.-L. Ma, and Z.-D. Zhou. 2014. Evaluation and selection of Camellia osmantha germplasm resources (in Chinese with English abstract). Nonwood Forest Res. 32:159-162.

Xiong, B., D. Sumner, and W. Matthews. 2014. A new market for an old food: The U.S. demand for olive oil. Agr. Econ. 45:107-118.

Yang, C., X. Liu, Z. Chen, Y. Lin, and S. Wang. 2016. Comparison of oil content and fatty acid profile of ten new Camellia oleifera cultivars. J. Lipids, doi: 10.1155/2016/3982486.

Yao, X.H., K.L. Wang, X.F. Luo, H.D. Ren, B.C. Gong, and X.Q. Fei. 2005. The present state and development of industrialization of oiltea camelia (in Chinese with English abstract). China Forestry Sci. Technol. 19:3-6.

Ying, G.H., M.L. Lv, Z.W. Xue, and L.L. Li. 2015. Experimental study on Lentinus edodes cultivated with Camellia oleifera shell in autumn (in Chinese with English abstract). Edible Fungi of China 34:19-21.

Zhang, J.P., L.S. Hu, Z.L. Wang, M.H. Du, and X.H. Yao. 2015. Present situation and prospective of camellia nut shells utilization. Open J. For. 5:740-748

Zhang, D.Q., W.X. Peng, Q.M. Liu, Q.Z. Ma, X.F. Tan, H.P. Chen, and H. Tian. 2008a. Py-GC/ MS analysis to estimate high-grade resource recovery of Camellia oleifera shell (in Chinese with English abstract). J. Chinese Cereals Oils Assoc. 23:161-165.

Zhang, D., L. Stack, R. Zhang, J. Yu, B. Xie, Y. Chen, and J.M. Ruter. 2008b. Teaoil camelliaeastern "olive" for the world. ISHS Acta Hort 769:43-48

Zhao, J., S. Chen, G. Zen, and M. Zhang. 2015. Thinking of expanding planting Camellia oleifera trees. J. Chem. Pharm. Res. 7:21632166.

Zheng, J., H. Liu, and L. Zhou. 2011. Evaluation of Camellia oleifera as a source for biodiesel production, p. 1551-1554. International Conference on Electrical and Control Engineering, Yichang, Hubei.

Zhong, H., D.R. Bedgood, Jr., A.G. Bishop, P. Prenzler, and K. Robards. 2007. Endogenous biophenol, fatty acid and volatile profiles of selected oils. Food Chem. 100:1544 1551.

Zhong, H.Y., C.N. Wang, and B.X. Xie. 2001. The effect of supercritical $\mathrm{CO}_{2}$ extraction conditions on the quality of oil-tea camellia seed oil (in Chinese with English abstract). J. Chin. Cereals and Oils Assoc. 16:9-13.

Zhuang, R.L. 2008. Chinese oil-tea Camellia. 2nd ed. Chinese Forestry Publishing House, Beijing, China. 